\title{
La responsabilidad del Estado legislador y su subordinación a los efectos temporales de las sentencias de la Corte Constitucional ${ }^{1}$
}

\author{
The Legislative State responsibility and its subordination to the temporal \\ effects of the judgments of the Constitutional Court
}

William Ulrich Astaiza

Universidad Cooperativa de Colombia

\begin{abstract}
RESUMEN El presente artículo propone observar las dificultades que giran en torno a la responsabilidad del Estado por el hecho del legislador y cómo, mediante los efectos moduladores temporales de las sentencias de la Corte Constitucional (Ex tunc y Ex nunc), se ha llegado a una situación donde se ve en riesgo la aplicación de lo establecido en la cláusula general de responsabilidad. En efecto, no podrá hablarse de responsabilidad del Estado si no existe el binomio inexequibilidad-efectos moduladores retroactivos, creándose así un requisito que no exige la carta.
\end{abstract}

PALABRAS CLAVE Responsabilidad del Estado, efectos moduladores, Estado legislador, Consejo de Estado, inexequibilidad.

ABSTRACT This article proposes to observe the difficulties that revolve around the liability of the State for act of the legislator and how, through the temporary modulating effects of the Constitutional Court's rulings (Ex tunc and Ex nunc), a situation has been reached where the application of the provisions of general liability clause is at risk. Indeed, it will not be possible to speak of the liability of the State if the binomial of unconstitutionalityretroactive modulatory effects does not exist, thus creating a requirement that the Constitution does not demand.

KEYWORDS State responsibility, modulatory effects, legislative State, Council of State, unforceability.

1. Artículo resultado de la tesis de maestría titulada «Los efectos moduladores temporales de la Corte Constitucional y su influencia en la jurisprudencia del Consejo de Estado, una dificultad para la doctrina de la responsabilidad del Estado legislador», presentado a la Universidad del Cauca, sustentado y aprobado el 7 de abril de 2017 . 


\section{Introducción}

La responsabilidad del Estado legislador fue, en su principio, una teoría que no tenía posibilidades de aceptación, esto es, la escuela clásica francesa no aceptó la posibilidad de que se responsabilizara al Estado por actos que se consideraban de "soberanía» (Lafèrriere, 1888), bajo el entendido de que el órgano legislativo era elegido por el pueblo y reflejaba la voluntad de este; luego, no podía equivocarse en una especie de aplicación del principio del derecho anglosajón rex non potest peccare, de ahí que existiera una gran reticencia para la aceptación de este revolucionario modelo.

El Consejo de Estado francés, en su Arrêt Duchâtellier de 1838, estableció que el Congreso - en su facultad creadora de normas- no podía comprometer la responsabilidad pecuniaria del Estado. No existe una condición excepcional donde se ponga a un ciudadano en una situación de sufrir un daño de carácter excepcional, ya que la ley tiene la cualidad de ser general y no de naturaleza particular. Es así como el máximo ente administrativo francés, en un inicio, se separó de aceptar que dicha responsabilidad era posible, poniendo de por medio la naturaleza abstracta y general de la ley, dejando por fuera cualquier posibilidad de indemnización para aquellos que lo buscaren.

No obstante la imposibilidad prima facie que se presenta sobre la responsabilidad del Estado por el hecho de sus leyes, siempre habrá un movimiento contrario que propugnará desde la disidencia argumentativa buscar un camino diferente que encuentre la posibilidad jurídica de reconocer aquella responsabilidad, cuestión que tuvo su cuna en el mismo lugar desde donde se negó, cien años después, en la Arrêt La Fleurette de 1938, donde se dio un revolcón a la ya establecida teoría de la irresponsabilidad del Estado por el hecho de sus leyes y se reconoció como una cuestión posible y aplicable (Jinesta, 2005).

El Consejo de Estado de Colombia y su connotado corte francés no es ajeno a estas teorías y su aplicación, tal y como lo establecen Malagón y Gaitán (2008: 166-170), donde ya entrado el siglo XX se presentó un primer caso en el que se discutía la posibilidad de responsabilizar al Estado por una norma. En este primer momento se presentó sobre una norma de carácter departamental, aunque si bien no era una norma en el estricto sentido, sí fue un primer momento que condujo a que se considerara la posibilidad de llevar a una discusión mucho más fuerte este importante tema. ${ }^{2}$

El avance en la materia no ha sido en lo absoluto pacífico, ya que adelantada la discusión acerca de si la responsabilidad del Estado colombiano procede o no, nos encontramos con muy singulares acercamientos por parte del Consejo de Estado sobre cómo se logra esta especial responsabilidad y, más concretamente, se presenta una muy curiosa simbiosis entre los efectos moduladores temporales en las sentencias de la Corte Constitucional y los fallos de responsabilidad del máximo ente de lo contencioso administrativo en Colombia, que se abordará en su debido momento.

2. Consejo de Estado de Colombia, sentencia 5.396, 18 de octubre de 1990. Consejero ponente: Julio César Uribe Acosta. Disponible en: http://bit.ly/2nE7ADh 
Pero, como antes se explicó, el progreso que muestran estos temas siempre tendrá bifurcaciones discursivas que atacan el ser mismo de estos planteamientos, y en el seno de la sección tercera esta discusión se dio a partir del planteamiento de que no es posible poner obstáculos a la responsabilidad del Estado que están estrictamente señalados en la Constitución Política, cuestión que añade argumentos a este fascinante análisis.

Es necesario entonces proceder a analizar de forma juiciosa este tipo de responsabilidad empezando, como es prudente, por los antecedentes históricos del tema. y pasar a su aplicación y análisis dentro del ordenamiento jurídico colombiano que, como ya se dijo, propone matices de necesaria observación para aquellos que encuentran problemática y poco discutida esta teoría.

\section{El análisis de la responsabilidad del Estado legislador en la jurisprudencia del Conseil d'État francés}

Como ya se explicó, la responsabilidad del Estado por el hecho de sus leyes tiene como origen la jurisprudencia del Consejo de Estado francés, que en su primer momento se apegó a la doctrina clásica del tema, que propugnaba por una irresponsabilidad del Estado basada en la idea de los actos de soberanía, con el siguiente argumento: «[...] Es el principio de que los daños causados a los particulares por las medidas legislativas no tendrán derecho a indemnización. La ley es de hecho un acto de soberanía [...] ninguno puede reclamar su compensación» (Laferrière, 1888: 12).

El primer fallo en adentrarse en este espinoso tema fue el Arrêt Duchâtellier de 1838, que proponía, en apego a la doctrina clásica que negaba la responsabilidad del Estado por la prohibición de la comercialización de un tabaco diferente al clásico, es decir, un tabaco falso, lo que naturalmente perjudicó a la empresa que comerciaba con este producto, dejando indemne al Estado en virtud de la teoría que se analizó.

El cambio en la postura del Consejo de Estado galo se produce cien años después, con el Arrêt La Fleurette de 1938 que, en similares circunstancias fácticas a lo ocurrido con el Arrêt Duchâtellier, prohibió la comercialización de un producto, que en este caso no sería el tabaco, sino la crema de leche. La ley de 29 de junio de 1934 prohibía:

Fabricar, exhibir, ofrecer a la venta o venta, importación, exportación o tránsito: 10) bajo el nombre de «crema» seguido de un nombre de fantasía, un producto que representa en apariencia la crema, que no se derive exclusivamente de la leche, la adición de grasa extraña también está prohibida. ${ }^{3}$

Con esta disposición resultó afectada la sociedad de productos lácteos La Fleurette, que utilizaba un sucedáneo de la crema de leche a base de maní y huevos, llamado «Gradine», lo cual estaría prohibido por dicha norma.

El fin de la norma era la protección de la salubridad pública, lo que evidentemente

3. Consejo de Estado de la República Francesa. Arrêt La Fleurette, 14 de enero de 1938. Texto original en francés disponible en: http://bit.ly/2BFUWvY 
no resultaba afectado con un producto que simplemente estaba hecho a base de productos diferentes a los lácteos, imponiendo así una carga desproporcionada e injusta a la empresa La Fleurette, que naturalmente solicitó las reparaciones que le eran justas por los perjuicios ocasionados (Long y otros, 2015).

La sentencia condenó al Estado bajo los siguientes argumentos: a) la actividad prohibida por la ley no tenía carácter nocivo; b) el perjuicio fue sufrido específicamente por la empresa; c) el legislador tomó en consideración la protección de otros intereses productivos o industriales y d) se le impuso a una empresa una carga que no le correspondía en condiciones normales (Arrêt La Fleurette, 1938).

Resulta también importante destacar que el fallo trae consigo una aclaración que no está de más incluir, respecto a que no solo los fallos de la jurisdicción podrán ser tenidos como elementos de responsabilidad del Estado (Arrêt Couitéas, 1923) sino además las leyes en sentido formal que son, por antonomasia, las leyes expedidas por el órgano legislador.

Visto lo anterior, resulta evidente porqué es tan importante este fallo y como de tajo dio al traste con un siglo de tradición en el sentido de impedir que las leyes fueran elementos de responsabilidad del Estado. Es claro que no es posible desvincular las actuaciones del Estado de las de sus órganos; en este caso el órgano legislativo pertenece de manera plena a esa estructura que es el Estado y no es posible escindirlo tampoco en ninguna circunstancia del mismo, con lo cual se logra hacer la inclusión del legislativo como posible autor de daños que deben ser reparados por el Estado.

El precedente establecido por el fallo de La Fleurette es histórico y propone una variante para la jurisprudencia posterior, lo que se debe al cambio brusco - pero, como vimos, quizás un poco previsible - que se venía fraguando con las modificaciones propuestas por el Consejo de Estado Francés que privilegió, por encima de la soberanía de la ley, el principio de igualdad ante las cargas públicas (Quintero, 2013: 3-4). Esto aunado al hecho de que el juez deberá agotar, como lo indica Santamaría Pastor (1972: 85-92), el análisis sobre la voluntad del legislador en el sentido de esclarecer si existió voluntad o no de indemnizar los efectos de la ley, que de ser negativa deberá aplicar esta y, de no haber tal pronunciamiento del legislador, deberá el juez con carga probatoria del demandante establecer cuál era la voluntad.

Continuando con el análisis de los antecedentes históricos sobre la responsabilidad del Estado por el hecho del legislador, tenemos como segundo momento relevante el Arrêt Bovero de 1963, que propone un caso bastante especial: se presenta un desahucio por parte de un propietario de un bien inmueble buscando la restitución de este, la cual fue obtenida. Sin embargo, no fue posible llevar a cabo su ejecución judicial debido a una norma que prohibía la expulsión del alojamiento de los militares y las familias de los militares que servían en el norte de África, más concretamente en Argelia (Ybarra, 2009: 73-74); esto, como es obvio, generó una disputa, ya que el prefecto - quien conocía de la existencia de la norma - se negó a la ejecución de la orden de desalojo (Checa, 2004:52-53).

El daño que se produce es evidente y es posible que lo sufriera un porcentaje con- 
siderable de la población francesa de aquel entonces; esto es, aquellos que arrendaran un bien a una familia que tuviera un pariente en la guerra que vivía Francia en Argelia, uno de sus territorios de ultramar que buscaba su independencia. Es comprensible la razón detrás de esta ley del 3 de enero de 1959, que era la protección de la familia de estos militares de ser lanzados de sus viviendas por el hecho de tener parientes sirviendo en África.

Los cambios planteados por el fallo Bovero son relevantes. Como tuvimos ocasión de analizar, al principio de la línea jurisprudencial del Consejo de Estado se buscaba indagar sobre la voluntad del legislador y si este había omitido expresarse sobre la indemnización. El fallo Bovero, al guardar silencio sobre dicha materia, incluyó la posibilidad de que, al no existir un pronunciamiento expreso sobre el tema de la indemnización, esto operara como una presunción a favor del accionante, invirtiendo la carga de la prueba hacia el legislador, quien en todo caso debería pronunciarse sobre el tema buscando evitar su condena.

Como podemos ver, Francia es la cuna de este tipo de responsabilidad; es aquí donde el nacimiento de la problemática encontró una solución que evadía a los postulados clásicos como el de Lafèrriere (1888: 12) que, sin más, estaban llamados a desaparecer ante el peso de una nueva línea de pensamiento que acabaría proponiendo una teoría completamente diferente a la que originalmente se venía manejando.

\section{Los efectos moduladores temporales de la Corte Constitucional}

La Corte Constitucional, en uso de lo establecido por el artículo 45 de la Ley 270 de 1996, tiene la posibilidad de modular los efectos de sus sentencias ya sea Ex nunc o hacia el futuro, que resulta ser la regla general, ya que a falta de un pronunciamiento en este sentido por parte de la Corte en sus fallos de constitucionalidad, se entenderá que este rige hacia el futuro, lo cual fortalece la seguridad jurídica. Ahora bien, se puede, de manera excepcional, llevar los efectos de las sentencias hacia el pasado - Ex tunc-, que resulta ser una cuestión extraordinaria y que obedece a criterios de protección de los derechos de las personas que, de no procederse de esta forma, estarían inmersos en una situación atentatoria a sus derechos.

Los efectos Ex nunc, tal y como le establece la Corte Constitucional, serán la regla general en el normal devenir de las sentencias, ${ }^{4}$ ya que para estos casos lo más importante será la protección de la seguridad jurídica con la irretroactividad en los pronunciamientos de la Corte que podrían generar inestabilidad jurídica, además de la confianza que genera para la población el saber que las situaciones jurídicas consolidadas no serán cambiadas a la luz de efectos retroactivos.

La escuela austríaca, relacionada estrechamente con el tratadista Hans Kelsen (Quiroga Lavié, 1961: 117), aboga por un sistema de irretroactividad de los efectos de las

4. Corte Constitucional de Colombia, sentencia C-037, 1996. Ministro Ponente (en adelante M.P.) Vladimiro Naranjo Mesa Rad: P.E. oo8. Disponible en: http://bit.ly/1FnDHs7 
sentencias (Olano García, 2004: 584), tanto así que (Olano García, 2004: 584) defiende las facultades que posee un tribunal constitucional para implementar un régimen de transición que permita no jugar con la estabilidad social y económica de los asociados, naturalmente con cierto tipo de controles temporales que permitan a las personas ajustarse a los cambios proferidos, lo cual es enteramente razonable. La crítica a este modelo proviene de una postura muy real que plantea la dificultad de someter a un ciudadano a que acepte una norma y sus efectos aun a pesar de haber sido declarada inexequible.

Los fallos de naturaleza Ex tunc -o «desde siempre», de su traducción del latínson el resultado de la obligación de la Corte de proteger los derechos de las personas de la mejor forma posible, es decir, se produce una extensión de los efectos de la declaratoria de inexequibilidad de una norma hacia el momento mismo en que produjo efectos, con lo cual se busca evitar inequidades y situaciones que resultarían dañinas o injustas para las personas (Vargas, 2011: 19-20).

Resulta polémico el uso de este tipo de poderes, ya que como se extrae de la Ley 270 de 1996, tiene la Corte Constitucional la amplitud dentro de sus competencias de determinar cuándo utilizar esta facultad que, como lo establece la misma Corte, ${ }^{5}$ ha sido un tema de amplio estudio, ya que se están retrotrayendo los efectos de una sentencia hasta la creación misma de una norma que el tribunal constitucional ha considerado expulsar del ordenamiento.

En el ámbito internacional no es uniforme el uso de esta facultad. Olano García (2004: 583) expone que en Alemania, Bélgica, Portugal y España la regla es que sus efectos sean hacia el pasado, y existen otros, como Austria y Polonia, donde se aplica lo contrario en idéntica forma. Nogueira Alcalá (2001: 369-382) expone que en países latinoamericanos como Perú, Bolivia y Colombia, el empleo de esta facultad es de uso indistinto, es decir, el tribunal podrá, dentro de sus facultades, establecer si usa uno o el otro.

El análisis de este tema no es pacífico, ya que no se encuentra un patrón que permita entender en qué momento se aplicará de forma cierta la facultad de llevar hacia el pasado los efectos de un pronunciamiento de constitucionalidad; es por esta razón que sus apariciones esporádicas son objeto de análisis.

\section{La responsabilidad del Estado legislador, aproximación doctrinal y jurisprudencial}

La responsabilidad del Estado por el hecho del legislador se da a partir de la promulgación de una norma - puede ser esta de tipo tributario, pensional, monopolística, etc.que genera un perjuicio a manera de daño especial, es decir, se origina en un elemento legítimo, como lo es la ley misma, que crea una carga que no está obligada a soportar

5. Corte Constitucional de Colombia, sentencia C-619, 2013. M.P. Clara Inés Vargas Rad: R.E. 131. Disponible en: http://bit.ly/2GRiVaQ 
un ciudadano, posibilitando como tal al afectado para presentar el medio de control de la reparación directa para generar la responsabilidad patrimonial (Peña Mateus, 2012).

En países como Alemania e Italia, en la responsabilidad del Estado por los actos del legislador no hay propiamente un régimen que permita declarar la responsabilidad tal y como lo enuncia Ruiz (2010: 170-171), donde queda claro que, para que ello proceda ,es necesario que el mismo legislador permita, dentro de la ley, que exista la posibilidad de demandar, o en el caso italiano, aun cuando la ley no lo establezca, se podrá lograr vía judicial.

En el caso español este tema ha avanzado mucho, ya que inicialmente partió - como en Colombia - con la doctrina de la irresponsabilidad del Estado, produciéndose así una especie de injusticiabilidad tal y como lo exponen Tejera y Herrera (2014: 1143), que posteriormente en fallos referentes a temas pensionales, tales como la sentencia del Tribunal Constitucional sobre la constitucionalidad del Decreto-ley 17 de 1982 y la sentencia de la Sala Plena del Tribunal Supremo de 25 de septiembre de 1987, se dejan sentados antecedentes jurisprudenciales de importante calado.

Ya no es un tema de discusión en la jurisprudencia del Consejo de Estado ni de la Corte Constitucional la existencia de este tema, ya que el tratamiento que ha extendido el primero ha llevado a materias como las expresiones normativas de tipo departamental (ordenanzas) ${ }^{6}$ a situaciones donde intervienen temas referentes a hechos de agentes diplomáticos, donde estos, valiéndose de su inmunidad, no pueden ser sujetos a los rigores de un juicio en Colombia, razón por la cual se hace responsable al Estado por la suscripción de una normatividad que impide a los ciudadanos recibir una indemnización frente a los perjuicios que estos están en plena capacidad de probar, pero que, debido a lo mencionado, no les es posible. ${ }^{7}$

La Corte Constitucional ha dejado sentado un interesante precedente frente a este tema, quedando claro cuáles son los requisitos para que proceda la responsabilidad del Estado, sin interesar si este ente es el Legislativo:

Tal como lo ha entendido el Consejo de Estado, la disposición constitucional que regula la materia establece la obligación de reparar los daños antijurídicos provenientes de cualquier autoridad pública. En efecto, como se ha reiterado, el precepto simplemente establece dos requisitos para que opere la responsabilidad patrimonial estatal, a saber, que haya un daño antijurídico y que este sea imputable a una acción u omisión de una autoridad pública, sin hacer distingos en cuanto al causante del daño $[\ldots]{ }^{8}$

De la misma forma lo ha entendido el Consejo de Estado, que es enfático en esta-

6. Consejo de Estado de Colombia, sentencia 5.396, 18 de octubre de 1990. Disponible en: http://bit. ly/2nE7ADh

7. Consejo de Estado de Colombia, sentencia IJ-oo1, 25 de agosto de 1998. Consejero ponente: Jesús María Carrillo Ballesteros. Disponible en: http://bit.ly/2FMiAFa

8. Corte Constitucional de Colombia, sentencia C-038, 2006. M.P. Humberto Antonio Sierra Porto Rad: D 5839. Disponible en: http://bit.ly/2GOLV30 
blecer que de ninguna manera puede el legislativo excusarse de su responsabilidad so pretexto de su estatus de depositario de la facultad soberana de crear las leyes, en este sentido establece:

Es uno de aquellos eventos de responsabilidad por el hecho del legislador, donde el Congreso de la República, pese a su poder soberano de representar al pueblo con sus decisiones, puede causar un daño que la persona no esté en deber jurídico de soportar, ora por supuestos en que se impide el acceso a la administración de justicia, bien porque la ley es declarada inexequible, o ya sea porque el mismo ordenamiento prevé la obligación de indemnizar. 9

El Consejo de Estado en sus pronunciamientos ofrece - al igual que la imputación por daño especial - la curiosa variante de la falla en el servicio legislativo, defendido en la Sección Tercera 28.741 de 2014, ${ }^{10}$ donde propone que podrá presentarse esta figura bajo el entendido de que la norma declarada inexequible lo fue siempre, y que los daños que ocasionó dicha norma espuria se generaron desde el momento de su expedición, lo cual genera una falla en el servicio por una prestación deficiente en este vital servicio.

No ha pasado inadvertida esta postura; la Sección Cuarta, mediante sentencia de tutela suspendió los efectos del arriba mencionado fallo, exponiendo lo siguiente:

Los argumentos hasta aquí expuestos llevan a una conclusión palmaria: la sentencia censurada se equivocó al imputar al Congreso de la República un daño que ni siquiera produjo, pues, si se admitiera que existe un daño reparable, el llamado a responder no es el Congreso de la República, sino la entidad recaudadora del tributo en favor de la Nación, es decir, la DIAN, siempre y cuando esta hubiera sido la causante de un daño antijurídico, cosa que no sucedió, como cuando persiste en recaudar tributos derivados de leyes inexequibles, lo que no ocurrió en este caso."

Aun a pesar de esta posición contraria de la Sección Cuarta del Consejo de Estado persiste la posibilidad de que esta postura — que si bien se vio suspendida en algún momento- vuelva y cobre fuerza, ya que como planteó la sentencia inaplicada, la antijuridicidad que exige la cláusula general de responsabilidad se da en el momento mismo en que es promulgada la norma que luego se ve expulsada del ordenamiento por la Corte Constitucional y, resultaría curioso que no se observara con juicio lo establecido en el artículo 16 de la Ley 446 de 1998, que busca en los procesos que se surtan ante la

9. Consejo de Estado de Colombia, «Sentencia 28.221, 24 de abril de 2013. Rad: 44001-23-31-000-200200457-01. Consejero ponente: Olga Mélida Valle de la Hoz». Sala Plena Contenciosa-Administrativa, Sección Tercera, 24 de abril de 2013. vLex (VLEX-438001774)

10. Consejo de Estado de Colombia, «Sentencia 28.741, 26 de marzo de 2014. Rad: 2500o-23-26-ooo2003-00175-01. Consejero ponente: Enrique Gil Botero». Sala Plena Contenciosa-Administrativa, Sección Tercera, 26 de marzo de 2014.vlex (VLEX-560445422)

11. Consejo de Estado de Colombia, Sección Cuarta, Fallo de Acción de Tutela 11.001-03-15-000-201402171-0o, o7 de abril de 2016. Consejera ponente: Martha Teresa Briceño de Valencia. Disponible en: http://bit.ly/2nDU4iN 
administración de justicia observen el principio de la reparación integral. ${ }^{12}$

Ruiz (2010: 165) propone una preocupación que es bastante real frente a la responsabilidad del legislador, esta es la petrificación del sistema legal por el temor a verse enfrentados a constantes juicios a razón de leyes que puedan ser declaradas inexequibles. La petrificación del sistema se podría dar por el hecho de que el legislativo se abstenga de cumplir a cabalidad su tarea, lo que ha generado un temor a aceptar en pleno este tipo de responsabilidad, ya que podría producir esta desaceleración en la producción de necesarias normas que, debido a la constante mutación social que sufre un país, se hacen indispensables.

Aparece un tema que no es posible desatender en este análisis de la responsabilidad del Estado por el hecho de sus leyes: el de la confianza legítima (García de Enterría, 2002), que establece que, donde se ha creado para el administrado una situación que viene dotada de buena fe y que, ante un cambio intempestivo, puede generar una reparación para aquel que ha visto vulnerada esta expectativa legítima frente al actuar del Estado (González, 1996).

La figura de la confianza legítima puede ser rastreada a la jurisprudencia del Tribunal Contencioso Administrativo de Berlín (Coviello, 2013: 13-14), donde en un emblemático caso denominado la "viuda de Berlín» (Letelier, 2014: 612-645) de 14 de noviembre de 1956, se certificó que si una viuda de un funcionario de la República Democrática Alemana se trasladara a vivir a Berlín del Oeste (Alonso Pampliega, 2015) se le concedería una pensión. El traslado se llevó a cabo y para ello se hicieron los gastos necesarios; luego, se comprobó que ella no cumplía con las condiciones necesarias para acceder a la pensión y en consecuencia se le solicitó que devolviera las cantidades recibidas; el tribunal falló a favor de la viuda, ya que obligarla a devolver los dineros implicaría una violación a la confianza legítima que se generó con la certificación del Ministerio y que en razón a ello se habían hecho gastos para tal traslado (Cortés, 2008: 17-18).

Analizado ya desde el punto de vista de la doctrina y la jurisprudencia sobre la responsabilidad del Estado legislador, se hace claro que si bien el tratamiento que se le ha dado al tema es amplio, persisten muchas dudas que son muy complicadas de esclarecer y que aún no ha abordado la jurisprudencia. En Colombia el tema ha tenido, desde 1990, un avance importante, sin embargo, es tímido en cuanto a que no ha sido posible su reconocimiento total, quizás por las razones antes expuestas (petrificación del sistema legislativo) o quizás porque el volumen de posibles demandas solicitando indemnizaciones por daños antijurídicos sufridos crearía un grave problema económico para el Estado. No obstante esto, no es razón suficiente para que el avance de la legalidad siga su curso y finalmente se pueda permitir este importante avance de reconocer una plena y absoluta responsabilidad del Estado legislador, con el trasfondo de un ejercicio legis-

12. El citado artículo reza: «Valoración de daños. Dentro de cualquier proceso que se surta ante la Administración de Justicia, la valoración de daños irrogados a las personas y a las cosas, atenderá los principios de reparación integral y equidad y observará los criterios técnicos actuariales». 
lativo mucho más consciente y juicioso que, en resumidas cuentas, permitirá que desaparezca el temor de un sistema que no cambia por no ser demandado (Arango, 2009).

\section{La jurisprudencia del Consejo de Estado Colombiano y los efectos moduladores de las sentencias de la Corte Constitucional, una relación de "facilitación»"}

La cláusula general de responsabilidad del Estado colombiano - contenida en el artículo 90 superior- establece, con gran claridad, que el Estado responderá por los daños antijurídicos atribuibles a ellos, causados ya sea por acción u omisión, dejando muy claro que no mediará ningún otro tipo de requisito para que se declare esta; aceptar cualquier otra posibilidad sería abiertamente contrario a la Carta y resultaría en un curioso sobreseimiento de una norma que es bastante clara, como lo es la contenida en la Constitución.

La jurisprudencia del Consejo de Estado ha planteado que para poder derivar la responsabilidad del Estado por el hecho de sus leyes es requisito - podría decirse que casi sine qua non- que la Corte Constitucional (en uso de las facultades que le atribuye el artículo 45 de la Ley 270 de 1996) haya llevado los efectos de la inexequibilidad de una norma hacia el pasado, ya que, de no haberse procedido así, se estaría hablando de la regla general de dicho artículo, que es de que los efectos serían Ex nunc o hacia el futuro. De la siguiente forma lo expresa el Consejo de Estado:

Conforme a lo anterior, no puede deducirse una responsabilidad del Estado cuando el alto Tribunal Constitucional haya declarado la inexequibilidad de una norma sin retroactividad, por cuanto los efectos generados hasta la declaratoria de la misma son válidos, y por lo tanto, el juez administrativo no puede desconocer que los efectos de la sentencia son hacia el futuro cuando no se exprese por parte de la Corte Constitucional lo contrario, siendo esta una facultad exclusiva otorgada por disposición del artículo 45 de la Ley 270 de 1996, el cual señala que «Las sentencias que profiera la Corte Constitucional sobre los actos sujetos a su control en los términos del artículo 241 de la Constitución Política, tienen efectos hacia el futuro a menos que la Corte resuelva lo contrario».13

Plantea la misma sentencia que está en juego el principio de legalidad del que estaba investido la norma expulsada, es decir, si los efectos no han sido Ex tunc o hacia el pasado, no cabría cuestionar la responsabilidad de la norma, ya que esta fue legal en todo sentido hasta el momento de su remoción del ordenamiento jurídico, teoría cuando menos problemática, tal y como lo estableció el Tribunal Constitucional en sentencia C-038 de 2006.

13. Consejo de Estado de Colombia, «Sentencia 28.864, 26 de marzo de 2014. Rad: 44001-23-31-0oo2001-00282-01. Rad: 4001-23-31-000-2001-00282-01. Consejero ponente: Jaime Orlando Santofimio Gamboa». Sala Plena Contenciosa-Administrativa, Sección Tercera, 26 de marzo de 2014. vlex (VLEX$522791506)$ 
El Consejo de Estado ha propuesto con esta teoría una extraña «facilitación» en todo el sentido de la palabra, siendo pues esta definición en palabras de (Stachowicz: 2001235): «Facilitative, or positive, interactions are encounters between organisms that benefit at least one of the participants and cause harm to neither. Such interactions are considered "mutualisms" when both species derive benefit from the interaction». ${ }^{14}$

El Consejo de Estado se ha puesto en posición de beneficiarse de los efectos moduladores temporales de las sentencias de la Corte Constitucional tal y como lo hacen los organismos vivos descritos en la anterior cita, sin causar ningún perjuicio a aquella; es decir, el Consejo de Estado se ha beneficiado de estos efectos para justificar su negativa a permitir una entrada plena de la responsabilidad del Estado legislador, lo cual resulta - por decir lo menos - muy curioso, ya que, como se explicó, la responsabilidad del Estado bajo ningún entendido está subordinada a efectos de las sentencias de otra jurisdicción (Armenta, 2014).

Esta posición - que ha tenido fuerza y se ha sostenido dentro de la corporaciónaboga por que la única forma de responsabilizar al Estado obedece a la observación de los efectos Ex tunc o Ex nunc de las sentencias de la Corte Constitucional, siendo pues casi un prerrequisito para acceder de forma «exitosa» a una reparación el que se hayan dado los primeros, y una señal de dificultades - por no decir fracaso- en las pretensiones del accionante que se dé la segunda (Sarmiento-Erazo, 2010).

Existe una postura disidente a este entendido que emana desde la misma Sección Tercera del máximo ente de lo contencioso administrativo que, atendiendo a criterios mucho más liberales sobre la materia, propone que no se debe atender a lo que estipula la Corte Constitucional, ya que una cosa es la responsabilidad del Estado en los estrictos y precisos términos de la cláusula general de responsabilidad contenido en la Constitución, y otra cuestión - muy diferente - son los pronunciamientos de inexequibilidad de la Corte, y bajo ningún entendido es requisito la una de la otra. Es decir, propone una ruptura de esa «facilitación» casi biológica que existe en la actualidad y deja libre al Consejo de Estado del apego a los efectos moduladores temporales de las sentencias de la Corte.

La Corte Constitucional se basó en el principio de seguridad jurídica para justificar el hecho de que las sentencias de constitucionalidad solo puedan tener efectos hacia el futuro. Sobre el particular, considera la Sala que pese a ser ello cierto, no obsta para que pueda accederse a la reparación del perjuicio, toda vez que una cosa es la intangibilidad de las situaciones jurídicas consolidadas antes de la declaratoria de inconstitucionalidad y otra muy diferente, es el deber que tiene el legislador de reparar el daño que ha causado con su actuación; se trata de situaciones jurídicas autónomas e independientes entre sí. ${ }^{15}$

14. "Las interacciones facilitadoras o positivas son encuentros entre organismos que benefician al menos a uno de los participantes y no causan daño a ninguno de ellos. Tales interacciones se consideran "mutualismos" cuando ambas especies se benefician de la interacción."

15. Consejo de Estado de Colombia, «Sentencia 28.741, 26 de marzo de 2014. Rad: 2500o-23-26-ooo- 
La resistencia en la aceptación de la plenitud de la responsabilidad del Estado por el hecho de sus leyes es una cuestión que se tornará, en un futuro no muy lejano, en la regla general, porque resulta insostenible que una persona que esté en la capacidad de probar que una ley que ha sido excluida del ordenamiento jurídico - independiente de si los efectos son a futuro o hacia el pasado- le ha causado un perjuicio, y que este no estaba obligado a soportarlo, no pueda — ni siquiera armado de pruebas pertinentes y conducentes - llegar a un proceso con una expectativa de ver prosperar sus pretensiones, esto bajo el entendido de que no existieron los efectos moduladores de naturaleza Ex tunc (Rivera, 2006).

El principio de la reparación integral propone una importante postura para la obligación de los operadores judiciales - más concretamente dentro del ámbito de lo contencioso administrativo - de considerar la posibilidad de aceptar la responsabilidad del Estado en materia de leyes como una oportunidad ad completa y no atada a pronunciamientos externos y que, básicamente, no tienen injerencia alguna sobre lo que es la responsabilidad del Estado como tal, ya que entender que la posibilidad de que el Estado colombiano responda por los daños antijurídicos cometidos se aleja de las facultades de la Corte Constitucional y radica en cabeza del Consejo de Estado.

La obligación del Estado, de acuerdo con lo estipulado en el artículo 2 de la Constitución Colombiana, deja claro que es una obligación de este proteger a todos los colombianos en su vida, honra y bienes. Esto pone en evidencia que la obligación de los jueces es atender a este principio para establecer claramente cuál debe ser el nivel de reparación que reciba una persona afectada por el actuar legítimo del Estado, es decir, cuando la norma -elemento legítimo del Estado- ocasione un daño, deberá el juez atender de forma juiciosa el caso analizando si existe, bajo la lupa del artículo 90 de la Constitución, un daño antijurídico cometido, ya sea por acción u omisión, para que opere la figura de la responsabilidad.

Toda reparación, parte de la necesidad de verificar la materialización de una lesión a un bien o interés jurídico tutelado (daño antijurídico), o una violación a un derecho que, consecuencialmente, implica la concreción de un daño que, igualmente, debe ser valorado como antijurídico dado el origen del mismo (una violación a un postulado normativo preponderante). ${ }^{16}$

Visto lo anterior, resulta indispensable analizar con mucho juicio lo que se ha dicho con respecto a que el Consejo de Estado ha subordinado sus resoluciones por la responsabilidad del Estado por el hecho de las leyes a los pronunciamientos de constitucionalidad de la Corte, lo cual es un interesante cambio, ya que generalmente las altas

2003-00175-01. Consejero ponente: Enrique Gil Botero». Sala Plena Contenciosa-Administrativa, Sección Tercera, 26 de marzo de 2014.vlex (VLEX-560445422)

16. Consejo de Estado de Colombia, Sección Tercera, sentencia 40.060, 20 de octubre de 2014. Rad: 05001-23-31-000-2004-04210-01. Consejero ponente. Enrique Gil Botero. Disponible en: https://bit. ly/1PobMKW 
cortes son reticentes a renunciar a sus poderes o inclusive a subordinarse a lo que les es impuesto por otras jurisdicciones, y en este caso, curiosamente, existe un sometimiento que naturalmente genera curiosidad.

La teoría del Consejo de Estado voluntariamente subordinada a los efectos moduladores temporales de la Corte Constitucional es un giro inesperado en lo que debe ser la responsabilidad del Estado. Esto se debe a que no es posible crear como requisito especial de acceso a la administración de justicia un argumento que no es constitucional, este es que para lograr un posible fallo favorable ante la jurisdicción de lo contencioso administrativo debe contarse de antemano con un pronunciamiento expreso de la Corte que extienda sus efectos hacia el pasado, lo cual no solo afecta al verdadero entender del acceso a la justicia - ya que tornaría cualquier pretensión que no cuente con este requisito como «frívola»-, sino que dejaría en entredicho el derecho a la igualdad, bajo el entendido de que sin mediar un argumento de peso, constitucionalmente hablando, se estaría dejando sin derecho a recibir un juicio justo a una persona que puede potencialmente probar sus perjuicios.

Los efectos moduladores temporales en las sentencias de la Corte Constitucional no fueron creados como requisito de acceso a la responsabilidad del Estado por el hecho del legislador, la Ley Estatutaria de Administración de Justicia las creó tan solo como posibilidades dentro de los pronunciamientos de la Corte para la protección de derechos particulares o como medida de protección a la seguridad jurídica.

La tesis del principio de legalidad como argumento de peso para sostener que los actos del legislador fueron válidos hasta que efectivamente se expulsó la norma del ordenamiento está construido sobre cimientos débiles, ya que dejaría por fuera la posibilidad de que por la existencia de título de daño especial pueda cuestionarse la responsabilidad del Estado mismo como se ha hecho en otras ocasiones. ${ }^{17}$

\section{Impase postural, la responsabilidad relativa del Estado legislador en la jurisprudencia del Consejo de Estado}

La jurisprudencia del Consejo de Estado es unánime: la responsabilidad del Estado por el hecho del legislador procederá, sobre una norma declarada inexequible, si y solo si frente a la declaratoria de inexequibilidad la Corte Constitucional hizo uso de los efectos moduladores temporales Ex tunc o hacia el pasado, lo cual ha quedado claro y hasta el momento es la tesis defendida por el máximo ente de lo contencioso administrativo.

No ha sido de recibo la postura liderada por el exconsejero Enrique Gil Botero ${ }^{18}$ que propugna por una responsabilidad completa en este sentido, cuestión que también quedó clara en el salvamento de voto del mismo consejero, que estableció que:

17. Consejo de Estado de Colombia, Sección Tercera, sentencia 6.805, 4 de septiembre de 1992. Consejero ponente: Julio Cesar Uribe Acosta. Disponible en: http://bit.ly/2Eg7Amp

18. Consejo de Estado de Colombia, «Sentencia 28.741, 26 de marzo de 2014. Rad: 250oo-23-26-ooo2003-00175-01. Consejero ponente: Enrique Gil Botero». Sala Plena Contenciosa-Administrativa, Sección Tercera, 26 de marzo de 2014.vlex (VLEX-560445422) 
No se comparten los argumentos expuestos y, por el contrario, he fijado mi posición en la materia para concluir que los daños provenientes del hecho de la ley -bien por omisión legislativa, por la ley exequible o constitucional, y por la ley declarada inexequible, con independencia de los efectos del fallo del Tribunal Constitucional- son de naturaleza antijurídica y, consecuencialmente, reparables de manera integral a la luz del artículo 16 de la Ley 446 de 1998. ${ }^{19}$

La dicotomía que se presenta es evidente, en el sentido de que este propugna por la figura de la responsabilidad en su plenitud, haciendo hincapié en el referido principio - el de reparación integral-, que en su obra "Responsabilidad extracontractual del Estado» — citando la sentencia C-197 de $1993-{ }^{20}$ deja claro lo que para él significa la reparación integral:

La reparación integral constituía un principio general en materia de responsabilidad: «se debe indemnizar el daño causado, todo el daño causado y nada más que el daño causado» o como lo ha expresado la Corte Constitucional, «el resarcimiento del perjuicio, debe guardar correspondencia directa con la magnitud del daño causado, mas no puede superar ese límite» (Gil Botero, 2013: 127-129).

Es posible que en aras de un ejercicio judicial más sano y garantista la aplicación de esta difícil teoría sea muy deseable para la jurisdicción contencioso administrativa en Colombia, ya que denegarla resulta injusto y constitucionalmente reprochable por las razones ya expuestas, esto es, que la misma Constitución no subordinó en ningún momento la responsabilidad del Estado a los efectos de ninguna sentencia ni de ningún prerrequisito, tan solo a la existencia del daño sin interesar si es por acción u omisión.

Se establece de igual forma que se está obrando por fuera de las funciones propias del juez al atribuirse la posibilidad de declarar responsable al Congreso por el hecho de sus leyes, que existe una incompetencia al hacerlo, ya que solo puede el legislador en uso de su soberanía y representación del pueblo dar, dentro de la misma ley, la posibilidad o no de que haya una reparación y que dentro del silencio del mismo legislador está la evidencia de que este jamás previó la posible existencia de un resultado antijurídico, cuestión que le compete al juez valorar y corregir sin inmiscuirse de ninguna manera dentro de la órbita de competencia de la rama legislativa.

Queda claro entonces que en la postura planteada los efectos son irrelevantes para la declaratoria de responsabilidad del Estado ya que no son estas las que establecen la responsabilidad. Ya que, la Corte Constitucional no se ocupa de dicha cuestión, será el

19. Consejo de Estado de Colombia, «Salvamento de Voto, Sección Tercera, sentencia 29.355, 20 de octubre de 2014. Rad: 25000-23-26-000-2003-00204-01. Consejero ponente: Jaime Orlando Santofimio Gamboa». Sala Plena Contenciosa-Administrativa, Sección Tercera, 20 de octubre de 2014. vlex (VLEX548276490)

20. Corte Constitucional de Colombia, sentencia C-197 de 1993. M.P Antonio Barrera Carbonell, Rad: R.E o38. Disponible en: http://bit.ly/2s9ZJlA 
juez de lo contencioso administrativo el que encargará de ello vía medio de control de reparación directa.

\section{La responsabilidad del Estado legislador en sus demás formas}

No en todas las ocasiones la materia de discusión se cierne sobre una norma que fue declarada inexequible y donde la Corte Constitucional no moduló los efectos temporales de su pronunciamiento, existe también la modalidad de la responsabilidad por normas que no han sido retiradas del ordenamiento o responsabilidad por normas exequibles y por omisión legislativa relativa, cuestiones que a continuación se analizarán.

La norma exequible es una derivación de la responsabilidad del Estado por el hecho del legislador, donde una norma que no ha sido cuestionada en su constitucionalidad causa un perjuicio que solo le es atribuible al Estado mismo por su suscripción, la cual ata de manos a un posible accionante, ya que no le es posible cuestionar su constitucionalidad y en muchos casos, como se verá, le imposibilita el acceso a la administración de justicia por la naturaleza propia de los hechos y los actores involucrados.

El caso más icónico de este tipo de responsabilidad se encuentra en la Sección Tercera IJ-001 de 1998, ${ }^{21}$ donde en un accidente de tráfico ocasionado por un agente diplomático ${ }^{22}$ de los Estados Unidos fallece un ciudadano colombiano. La Ley 6 de 1972 otorga inmunidad diplomática a ciertos funcionarios, cuestión aceptada por el legislador colombiano mediante ley aprobatoria, lo que imposibilita a un ciudadano a accionar solicitando la indemnización por sus perjuicios.

Dentro del presente establece el Consejo de Estado que existe una carga anormal que no está obligada a soportar la familia del fallecido y que esta se presenta en la forma de una ley vigente, creándose así un daño especial, ya que este es un elemento legítimo:

Por todo lo anterior es claro que, teniendo los nacionales el derecho a que se respete su integridad personal y patrimonial y a ejercer las acciones de ley para el restablecimiento de sus derechos conculcados, en igualdad de condiciones, en el caso presente los demandantes experimentan una doble limitación por virtud del privilegio de inmunidad jurisdiccional conferido por el Estado colombiano. De un lado porque quedan privados de la posibilidad de demandar en Colombia la reparación a que tienen derecho, en acción contra el ejecutor material del daño, y de otra parte porque consecuencialmente se desequilibraron las cargas públicas que deben soportar todos los ciudadanos en igualdad de condiciones $\left[\ldots .{ }^{23}\right.$

21. Consejo de Estado de Colombia, sentencia IJ-o01, 25 de agosto de 1998. Consejero ponente: Jesús María Carrillo Ballesteros. Disponible en: http://bit.ly/2FMiAFa

22. Dicha ley reza en su artículo 31: «El agente diplomático gozará de inmunidad de la jurisdicción penal del Estado receptor. Gozará también de inmunidad su jurisdicción civil y administrativa».

23. Consejo de Estado de Colombia, sentencia IJ-001, 25 de agosto de 1998. Consejero ponente: Jesús María Carrillo Ballesteros. Disponible en: http://bit.ly/2FMiAFa 
No podía ser otro el resultado que la declaratoria de responsabilidad por parte del Estado, no por la ley como tal, sino por el hecho de que, en determinados casos como el mencionado, se pone al ciudadano afectado en una situación de desventaja evidente, ya que para poder solicitar la reparación deben proceder aspectos en extremo complicados para cualquier persona, esto es, que el agente renuncie a su inmunidad.

Frente a la responsabilidad del Estado por omisión legislativa debe hacerse una primera precisión: procederá tan solo para la omisión legislativa relativa o parcial y no para la total, ya que, como resulta evidente, si no existe una ley será difícil atribuir la responsabilidad de ella al Congreso, que no obstante sus obligaciones está investido de la facultad de libre configuración en materia legislativa. Es decir, podrá decidir si expide o no una norma o si regula este u otro procedimiento, claro está, con el obvio límite de los derechos fundamentales. ${ }^{24}$

Resulta entonces menester establecer cuándo una omisión de parte del legislador puede resultar lesiva para un ciudadano, y la respuesta resulta similar a los anteriores casos planteados: será cuando con esta omisión se produzca una carga que no está obligado a soportar un ciudadano o, mejor dicho, cuando con esa omisión se le produzca un daño antijurídico a un ciudadano.

Frente a lo establecido en el artículo 90 superior, encuentra especial claridad este tipo de responsabilidad. Recuérdese que será responsable también por la omisión en sus funciones el Estado - y cuando se refiere a Estado no escapa a dicho criterio ninguno de los entes del mismo-, es decir, cualquiera de las tres ramas podrá ser responsable. Frente a la omisión se establece que:

La citada responsabilidad se imputa directamente al Estado a título de omisión antijurídica, por cuanto encontrándose el órgano del Estado obligado a producir una norma concreta para el desarrollo de un postulado constitucional porque así lo exige el ordenamiento, no lo hace ocasionando perjuicios a los derechos de los administrados. Surge la responsabilidad porque existiendo una obligación concreta de actuar no lo hace, y por ello al Estado legislador se le puede exigir el cumplimiento de la obligación de legislar, es decir de cumplir su obligación. ${ }^{25}$

Así las cosas, queda claro que este tipo de responsabilidad, si bien no es muy común, tiene precedente en materia constitucional y curiosamente no en materia contenciosoadministrativa, donde existe referencia tan solo en una aclaración de voto a la sentencia 28.864 - C.P. Jaime Orlando Santofimio que reza:

Los daños provenientes del hecho de la ley -bien por omisión legislativa, por la ley exequible o constitucional, y por la ley declarada inexequible, con independencia de los efectos del fallo del tribunal constitucional- son de naturaleza antijurídica y, con-

24. Corte Constitucional de Colombia, sentencia C-203, 2011. M.P. Juan Carlos Henao Rad: D- 8237. Disponible en: http://bit.ly/2BX4xdB

25. Consejo de Estado de Colombia, sentencia IJ-001, 25 de agosto de 1998. Consejero ponente: Jesús María Carrillo Ballesteros. Disponible en: http://bit.ly/2FMiAFa 
secuencialmente, reparables de manera integral a la luz del artículo 16 de la Ley 446 de $1998^{26}$.

La Corte Constitucional deja sentado un importante precedente al aclarar que la responsabilidad del Estado por omisiones legislativas procederá tan solo frente a aquellas de tipo relativo y no total, ya que esto supone, como ya se mencionó, una ausencia total de texto para su examen:

La omisión absoluta hace referencia al incumplimiento por parte del legislador de la obligación constitucional de expedir una regulación específica, es decir constituye una total inactividad por parte del Congreso y, por ende, supone la ausencia total de un texto o precepto legal. La Corte Constitucional se ha declarado reiteradamente incompetente para pronunciarse sobre esta modalidad de omisiones, con fundamento, entre otros, en los siguientes argumentos: (i) no es metodológicamente posible el examen de constitucionalidad en estos casos por la carencia de norma susceptible de control, (ii) es indispensable que la demanda de inconstitucionalidad recaiga sobre un texto real y no simplemente deducido por el actor o implícito, (iii) la declaración de inexequibilidad total o parcial de una disposición legislativa requiere previamente definir si existe una oposición definitiva y verificable entre lo que dispone el precepto acusado y lo que manda la Constitución. Finalmente, la ausencia de regulación de una determinada materia no necesariamente puede ser objeto de reproche constitucional, ya que los silencios del Legislador en determinados casos son expresiones de su voluntad. ${ }^{27}$

Queda claro entonces que es posible este tipo de responsabilidad y que por supuesto deberá probarse dentro de un proceso el perjuicio causado con la omisión que le sea atribuible al legislativo.

\section{Conclusiones}

La responsabilidad del Estado por el hecho de sus leyes es un modelo relativamente novedoso para Colombia y propone que un órgano que históricamente ha escapado a la lupa de la responsabilidad sea, hoy por hoy, considerado como un ente más, ya que es posible atribuirle lo estipulado en la cláusula general de responsabilidad del Estado, puesto que en ninguna parte se hace exclusión de este en el articulado constitucional y, más bien, cuando al Estado se refiere la Constitución, se entenderá este criterio como uno omnicomprensivo de todo lo relacionado al Estado.

El desafortunado y curioso hecho de que el Consejo de Estado haya subordinado sus pronunciamientos en esta materia a los efectos moduladores temporales de las sentencias de la Corte Constitucional es, como antes se relató, un hecho de interesantísimas proporciones para una investigación de talante jurídica, esto en atención a que un

26. Consejo de Estado de Colombia, Sección Tercera, Aclaración de Voto a la sentencia 28.864, 2014. Consejero ponente. Jaime Orlando Santofimio Gamboa. Disponible en: http://bit.ly/2nEsIZP

27. Corte Constitucional de Colombia, sentencia C-038 de 2006. M.P. Humberto Antonio Sierra Porto Rad: D 5839. Disponible en: http://bit.ly/2GOLV30 
ente tan especializado como lo es el Consejo de Estado se permita aceptar que debe, para el éxito de una pretensión, que haya habido efectos Ex tunc o retroactivos en una sentencia que declare la inexequibilidad de una ley, o de lo contrario estarán llamadas a fracasar las pretensiones de una demanda.

La timidez con que se ha acercado el Consejo de Estado al tema resulta también curiosa, ya que no se entiende que si se está en la posibilidad de probar un perjuicio que proviene de una norma que la Corte Constitucional no tuvo a bien realizarle una modulación de efectos tal y como lo establece la Ley Orgánica de Administración de Justicia, sea el ciudadano quien se vea obligado a ver fracasar sus pretensiones por el evidentemente inconstitucional supuesto que plantea el máximo ente de lo contencioso administrativo, ya que no está de más recordar, para la responsabilidad del Estado no hay otro supuesto que la acción u omisión y no que haya efectos moduladores temporales en las sentencias de la Corte.

Es evidente la necesidad de un cambio jurisprudencial y quizás, no se ve por qué no, una unificación jurisprudencial en este sentido, aun cuando esto parezca ambicioso, para evitar un arraigo de una teoría que tiene cimientos tan débiles como el de la actual responsabilidad del Estado legislador, lográndose así un verdadero acceso a la justicia para las personas que estén en capacidad de probar un daño antijurídico y, por supuesto, la igualdad jurídica para todos aquellos que - accediendo a proceso, donde el medio de control sea la reparación directa y el hecho dañoso una ley- puedan hacerlo sin el temor de una postura poco fructífera, como lo es la actual.

Los necesarios cambios también abarcan el ámbito de lo legislativo, ya que de aceptarse a plenitud esta teoría estaría en manos del legislador un cambio para mejorar de ostensible naturaleza, ya que de cualquier norma, sin importar qué efectos le sean impuestos por la Corte Constitucional en sus sentencias, procedería la responsabilidad. Debe haber un ejercicio mucho más académico, social y económico frente a las normas, ya que una legislación a la ligera presentará un eventual gasto por parte del Estado para cubrir las indemnizaciones que se pueden presentar.

Una cuestión que debe ser analizada con el debido cuidado es la del posible detrimento patrimonial que puede presentarse por las numerosas demandas que se estaría en la posibilidad de incoar por parte de aquellos que se crean afectados por el hecho del legislador. Es decir, el número de demandas aumentaría de forma alarmante, y si no hay una defensa efectiva para el ejercicio del legislador, posiblemente los gastos en los que deba incurrir la administración por las fallas legislativas son de considerar.

La responsabilidad del Estado en cuestiones tributarias sería considerable y, como se planteó antes, requiere de un ejercicio serio y sesudo por parte de los legisladores, quienes deberán estar muy bien asesorados a la hora de la expedición de una norma, ya que dejar pasar alguna con un vicio que pueda a posteriori generar responsabilidad sería, prima facie, causal suficiente para considerar la acción de repetición consagrada en la misma Constitución y la Ley 678 de 2001.

No obstante los indecisos pasos del Consejo de Estado, debe acotarse que los avances en Colombia son también dignos de respeto. La crítica se sostiene en el sentido de 
que la plenitud de la responsabilidad del Estado no resulta solo como un derecho para aquellos que puedan probar sus perjuicios, sino como una invitación a la mejora en las funciones del Estado mismo. El manejo de este tema no es sencillo y operar con la complejidad de los asuntos que se presentan es en extremo difícil, ya que hay de por medio pretensiones multimillonarias y, además, una presión política considerable sobre los consejeros de Estado.

\section{Referencias}

Alonso Pampliega, Sergio (2015). Interpretaciones e impacto cultural y social del Muro de Berlín. Trabajo de fin de Máster en Historia y Análisis Sociocultural, Facultad de Filosofía y Letras, Universidad de Oviedo. Disponible en: http://hdl.handle. net/10651/32613.

ArAngo, Daniel (2009). «El reconocimiento jurisprudencial de la responsabilidad patrimonial del legislador en Colombia». Revista del Instituto Antioqueño de Responsabilidad Civil y del Estado, 26. Disponible en: http://www.londonoyarango.com/ pdf/Articulo_Reconocimiento_Jurisprudencial_de_la_Responsabilidad_del_Legislador.pdf

Armenta, Karen (2014). «Modulación de los efectos temporales de las providencias de unificación del Consejo de Estado en Colombia». Diálogos de Derecho y Política, 13 , 47-70.

Checa, Clemente (2004). «La responsabilidad patrimonial de la administración pública con fundamento en la declaración de inconstitucionalidad de una ley». Ius et Praxis, 10 (1): 45-75.

CorTÉs, Josefina (2008). «Cambio regulatorio y seguridad jurídica, breves notas sobre el principio de confianza legítima». Berkeley Program in Law \& Economics. Disponible en: https://escholarship.org/uc/item/3h66p191.

Coviello, Pedro José Jorge (2013). «La confianza legítima». Estudios Jurídicos, 11: 9-70. García de EnTERría, Eduardo (2002). «El principio de protección del principio de la confianza legítima como supuesto título justificativo de la responsabilidad patrimonial del Estado legislador». Revista de Administración Pública, 159: 173-208.

Gil Botero, Enrique (2013). Responsabilidad extracontractual del Estado. 6. ${ }^{\circledR}$ edición. Bogotá: Temis.

GonzÁlez, Jesús (1996). Responsabilidad patrimonial de las administraciones públicas. Madrid: Civitas.

Jinesta, Ernesto (2005). «La Responsabilidad del Estado legislador». Revista de Derecho Público, 1. Asociación Costarricense de Derecho Administrativo, 1455-1494.

LAFERRIÈRE, Édouard (1887). Traité de la Jurisdiction administrative et des recours contentieux. París: Berger-Levraut et $\mathrm{C}^{\mathrm{IE}}$ Libraires-Éditeurs. Disponible en: http://gallica.bnf.fr/ark:/12148/bpt6k6503485t.

Letelier, Raúl (2014). «Contra la confianza legítima como límite a la invalidación de actos administrativos». Revista Chilena de Derecho, 41 (2): 609-634. 
Long, Marceau, Prosper Weil, Guy Braibant, Pierre Delvolvé y Bruno Genevois (2015). Les grands arrêts de la jurisprudence administrative. París: Dalloz.

Malagón, Miguel y Julio Gaitán (2008). Colonialismo cultural francés y la creación del Consejo de Estado en el derecho administrativo colombiano, , 115 (enero-junio de 2008), 161-178.Nogueira Alcalá, Humberto (2001). «Consideraciones sobre la tipología y efectos de las sentencias emanadas de tribunales o cortes constitucionales». En VVAA. Jurisdicción constitucional en Colombia - La Corte Constitucional 1992-2000, realidades y perspectivas. Bogotá: Edición de la Corte Constitucional y del Consejo Superior de la Judicatura, con el apoyo de la Escuela Judicial «Rodrigo Lara Bonilla» y de la Fundación «Konrad Adenauer».

Olano García, Hernán (2004). «Tipología de nuestras sentencias constitucionales». Vniversitas, 53 (108): 571-602.

Peña Mateus, Óscar (2012). Responsabilidad patrimonial del estado legislador en el derecho colombiano. Tesis doctoral, Facultad de Derecho de la Universidad Complutense. Disponible en: http://eprints.ucm.es/21019/1/T34415.pdf.

Quintero, Andrés José (2013). El daño especial como título jurídico de imputación de responsabilidad extracontractual por actos terroristas: su transición a fundamento de compensación. Tesis de maestría, Universidad Nacional de Colombia.

Quiroga Lavié, Humberto (1961). «La norma retroactiva en Hans Kelsen». Revista Lecciones y Ensayos, 23: 117-128.

RiverA, José Antonio (2006). «Los efectos de las sentencias constitucionales en el ordenamiento jurídico interno». Estudios Constitucionales, 4 (2): 585-609.

Ruiz, Wilson (2010). Responsabilidad del Estado y sus regímenes. Bogotá: Ecoe ediciones. Sarmiento-Erazo, Juan Pablo (2010). «Sentencias de la Corte Constitucional con efectos reparativos, entre el Juez Administrativo y el Juez Constitucional». Vniversitas, 121: 161-192.

Santamaría PAstor, Juan Alfonso (1972). «La teoría de la responsabilidad del Estado legislador». Revista de Administración Pública, 68: 57-136.

Stachowicz, John J. (2001). «Mutualism, Facilitation, and the Structure of Ecological Communities: Positive interactions play a critical, but underappreciated, role in ecological communities by reducing physical or biotic stresses in existing habitats and by creating new habitats on which many species depend». BioScience, 51 (3): 235-246.

Tejera, Evangelina y Pedro Manuel Herrera (2014). «La responsabilidad patrimonial del Estado legislador en el derecho español». Boletín Mexicano de Derecho Comparado, 47 (141): 1.137-1.164.

VArgas, Clara (2011). «La función creadora del Tribunal Constitucional». Derecho Penal y Criminología: Revista del Instituto de Ciencias Penales y Criminológicas, 32 (92): 1-21.

Ybarra, María Concepción (1999). La Argelia independiente: entre el socialismo y el fundamentalismo religioso. Madrid: Universidad Nacional de Educación a Distancia. 


\section{Sobre el autor}

William Ulrich Astaiza es abogado de la Universidad Cooperativa de Colombia, especialista y magíster en Derecho Administrativo de la Universidad del Cauca. Sus intereses de investigación son la responsabilidad del Estado y acciones públicas. Su correo electrónico es william.ulricha@campusucc.edu.co. 
